\title{
La sentencia es de quien la trabaja: estructura organizacional y justicia constitucional en México (1996-2005)
}

\author{
The judgment belongs to those who work it: \\ organizational structure and constitutional justice \\ in Mexico (1996-2005)
}

\section{Josafat Cortez Salinas, ${ }^{*}$ Camilo Saavedra Herrera**}

\author{
Licencia Creative Commons Atribución-NoComercial \\ (CC BY-NC) 4.0 Internacional \\ Perfiles Latinoamericanos, 29(58) | 2021 | e-ISSN: 2309-4982 \\ Dor: dx.doi.org/10.18504/pl2958-002-2021 \\ Recibido: 31 de octubre de 2019 \\ Aceptado: 13 de septiembre de 2020
}

\section{Resumen}

¿Qué papel desempeñan las estructuras que organizan el trabajo judicial en la labor de los órganos de justicia constitucional? Este artículo explora esta cuestión analizando la participación de la Unidad de Controversias Constitucionales y Acciones de Inconstitucionalidad (UCCyAI) en la elaboración de sentencias de la Suprema Corte de Justicia de la Nación durante el periodo 1996-2005. A nivel teórico, se ofrece una clasificación de las estructuras organizacionales de los órganos de justicia constitucional, lo que permite describir la experiencia mexicana de esos ańos como un modelo centralizado que dificultó el control de los integrantes del tribunal sobre la conformación de equipos de trabajo y la elaboración de sentencias. En el plano empírico, proponiendo a la UCCyAI como estudio de caso y mediante la sistematización original de más de mil expedientes, se concluye que la delegación en esa estructura fue significativa pues elaboró el $80 \%$ de las sentencias aprobadas en el periodo de estudio, y produjo uniformidad en las decisiones y criterios del tribunal.

Palabras clave: Suprema Corte de Justicia de la Nación, México, estructura organizacional, secretarios de Estudio y Cuenta, justicia constitucional, acciones de inconstitucionalidad, controversias constitucionales, comportamiento judicial, política judicial, América Latina.

\section{Abstract}

What role do organizational structures play in constitutional justice? This article explores the role of the Unidad de Controversias Constitucionales y Acciones de Inconstitucionalidad

* Doctor en Ciencia Política por la FLACSO México. Profesor del Centro de Estudios Políticos de la Facultad de Ciencias Políticas y Sociales de la Universidad Nacional Autónoma de México | josafatcortez@ politicas.unam.mx | orciD: http://orcid.org/0000-0001-6754-5177

** Doctor en Gobierno por la London School of Economics and Political Science. Investigador en el Instituto de Investigaciones Jurídicas de la Universidad Nacional Autónoma de México | camilos@unam .mx | ORCID: https://orcid.org/0000-0003-3247-0376 
(UCCyAI) in ruling drafting within the Suprema Corte de Justicia de la Nación along the period 1996-2005. At theoretical level, it proposes a first classification of the organizational structures for ruling drafting in constitutional justice institutions to contextualize the Mexican experience and show that, as a centralized structure, the Unit hindered justices' control over judicial recruitment and ruling drafting. Empirically, using the UCCyAI as a case study and employing an original dataset of more than thousand cases, the article shows, first, that the delegation of ruling drafting was extensive as the Unit's staff drafted the $80 \%$ of the Court's rulings in constitutional controversies and actions of unconstitutionality adjudicated in the period 1996-2005; and second, that such extensive delegation produced high levels of uniformity in decision-making and judicial interpretation.

Keywords: Suprema Corte de Justicia de la Nación, Mexico, organizational structure, law clerks, constitutional justice, constitutional review, judicial behavior, judicial politics, Latin America.

\section{Introducción ${ }^{1}$}<smiles>[TlH]</smiles>

a aprobación del presupuesto del gobierno federal en México es una atribución exclusiva de la Cámara de Diputados. Y aunque esta disposición existe desde 1917, en la práctica cobró sentido ochenta años después cuando el Partido Revolucionario Institucional (PRI) perdió el control de ese órgano. Para hacer frente a las tensiones que los gobiernos sin mayoría propiciaron desde su aparición en 1997, en junio de 2004 la Constitución federal determinó plazos que el Ejecutivo y el Legislativo deberían observar en los ejercicios subsecuentes. El presupuesto de 2005 fue el primero que se procesó bajo esas nuevas disposiciones. En esa ocasión, el Ejecutivo presentó el proyecto el 8 de septiembre de 2004, fecha límite contemplada en la Constitución, y la Cámara lo aprobó el 18 de noviembre, con tres días de retraso y modificaciones importantes.

El proceso no concluyó con dicha acción. El Ejecutivo realizó observaciones invocando el poder de veto que le confiere el artículo 72 constitucional. La Cámara las rechazó y le pidió por segunda vez que ordenara la publicación del documento. El Ejecutivo accedió y el texto se publica el 20 de diciembre en el Diario Oficial de la Federación; sin embargo, al día siguiente lo impugnó ante la Suprema Corte de Justicia de la Nación (scJN) mediante una contro-

1 Agradecemos el apoyo de Andrés Lucero Gil en la captura de una parte de los datos de la sistematización de sentencias utilizados aquí, así como los comentarios a una primera versión del texto que hicieron Juan González Bertomeu y los integrantes del Seminario de Estudios Empíricos del Derecho del Instituto de Investigaciones Jurídicas de la UNAM. 
versia constitucional. Como el tribunal se encontraba en periodo vacacional, la Comisión de Receso fue la instancia que admitió la demanda y concedió la suspensión que se solicitó para evitar la aplicación de partidas presupuestales por 6755 millones de pesos. Dos meses después, el 17 de febrero de 2005, el Pleno de la Corte confirmó la suspensión y falló en definitiva a favor del Ejecutivo para el mes de mayo.

Las consecuencias de la resolución no solo afectaron las relaciones Ejecutivo-Legislativo. El 17 de enero de 2005, un mes después de recibir la demanda y uno antes de confirmar la suspensión, la SCJN endureció las normas que regulan el "turno", es decir, el método que se emplea para la asignación de casos entre ministros. Más tarde, el 8 de marzo, disolvió la Unidad de Controversias Constitucionales y Acciones de Inconstitucionalidad (UCCyAI o Unidad, indistintamente), área que desde 1996 había estado a cargo de la tramitación de los asuntos relacionados con esos dos medios de control de constitucionalidad. La prensa reportó en su momento que la desaparición derivó, precisamente, de objeciones que plantearon algunos ministros respecto de la forma en que se manejó el turno y la calidad de las sentencias elaboradas por la UCCyAI, ${ }^{2}$ un área que trabajó para todos los ministros a quienes se encomendó instrumentar las innovaciones con las cuales la reforma judicial de 1994 había buscado transformar a la SCJN en un árbitro efectivo de la división de poderes y el federalismo.

¿Qué papel desempeñan las estructuras mediante las que se organiza el trabajo jurisdiccional dentro de los órganos de justicia constitucional en la labor de estos? En las décadas recientes, la investigación sobre el comportamiento judicial de la SCJN se ha concentrado en explicar las resoluciones a partir de factores externos al tribunal como el contexto político o la filiación y jerarquía de los litigantes (Ansolabehere, 2007; Cortez Salinas, 2014; Magaloni et al., 2011; Ríos Figueroa, 2004, 2016; Saavedra-Herrera, 2013). Solo algunos han explorado la influencia de factores internos como, por ejemplo, las trayectorias, las preferencias legales y las características sociodemográficas de los ministros (Castagnola \& López Noriega, 2016a, 2016b; Cuéllar, 2014, González-Ocantos, 2016), la antigüedad en el cargo (Saavedra-Herrera, 2013), la arquitectura institucional (Pou Giménez, 2016) o las prácticas y dinámicas de los operadores judiciales (Bárcena Arévalo, 2018). Hasta ahora ha sido muy limitado el estudio sistemático de la organización de la elaboración de sentencias y su relación con los actores en los que recae esta función: los secretarios de Estudio y Cuenta (Cortez Salinas, 2019).

Partiendo de la premisa de que las decisiones judiciales no solo están condicionadas por elementos externos a los tribunales y el contexto en el que se toman,

2 Por ejemplo, la nota de Fuentes (2005, 20 de marzo) en el periódico Reforma.

J. Cortez Salinas, C. Saavedra Herrera | La sentencia es de quien la trabaja: estructura organizacional y justicia constitucional en México (1996-2005) | Perfiles Latinoamericanos, 29(58) | FLACSO México DOI: dx.doi.org/10.18504/pl2958-002-2021 
sino también por las estructuras organizacionales a cargo de las actividades que supone el ejercicio de la función jurisdiccional, este artículo tiene como objetivo analizar el papel que desempeñó la UCCyAI en el trabajo jurisdiccional de la SCJN durante la década posterior a la reforma de 1994. Para ello utilizamos un diseño de investigación basado en fuentes oficiales y periodísticas, entrevistas a operadores jurídicos, así como una sistematización original de más de mil expedientes de acciones de inconstitucionalidad y controversias constitucionales que se presentaron en el periodo 1995-2005.

Con base en esa estrategia, y considerando que el trabajo de la Unidad constituye un estudio diacrónico de caso (Gerring, 2007), este análisis realiza dos aportaciones a la investigación empírica sobre estructuras organizacionales y justicia constitucional. El primero, de carácter teórico, es una clasificación de las estructuras organizacionales de los órganos de justicia constitucional, la cual sirve además para contextualizar el caso mexicano y resaltar las implicaciones que produjo la configuración de una estructura centralizada, que estuvo fuera del control directo de los jueces. El segundo, de carácter empírico, es que la conformación de estructuras centralizadas está asociada a la delegación de funciones y la uniformidad en las decisiones. La delegación es identificable en el hecho de que la UCCyAI elaboró el $80 \%$ de las sentencias relacionadas con acciones de inconstitucionalidad y controversias constitucionales en el periodo 1996-2005. Y la uniformidad se observa en que en $30 \%$ de esas sentencias se hayan invalidado las normas o actos impugnados, que el $82.8 \%$ se aprobara por unanimidad y que solo $18.6 \%$ fueran acompañadas por votos particulares.

El resto del texto se estructura de la siguiente manera: la primera sección analiza la literatura que desde la ciencia política se ha aproximado a la relación entre estructura organizacional y secretarios de Estudio y Cuenta, y presenta la clasificación antes mencionada; la segunda, describe el diseño de investigación y las fuentes de información; la tercera, examina la historia de la Unidad; la cuarta, muestra empíricamente que este órgano generó delegación y uniformidad a partir del análisis de la sistematización de sentencias previamente descrita. Se concluye con una recapitulación de los hallazgos y una reflexión acerca de sus implicaciones para la literatura sobre la SCJN y, en general, sobre los tribunales en América Latina.

\section{La relación entre estructura organizacional y justicia constitucional}

El modelo estratégico ha sido uno de los más importantes referentes teóricos de los estudios sobre comportamiento judicial en América Latina, particularmente en los que se centran en países que vivieron procesos de transición como Ar- 
gentina (Helmke, 2005; Iaryczower et al., 2002), Brasil (Taylor, 2008), Chile (Scribner, 2010) o México (Cortez Salinas, 2014; Magaloni et al., 2011; Ríos Figueroa, 2004, 2016; Saavedra Herrera, 2020). Pese al énfasis que los impulsores originales de este modelo pusieron en el contexto institucional interno (Epstein \& Knight, 1998), las investigaciones sobre la región han atendido poco este tipo de aspectos. Para decirlo en otras palabras, los esfuerzos por abrir la "caja negra" de la justicia han sido limitados.

La corriente de estudios que en los últimos ańos se propuso explicar el comportamiento judicial más allá del enfoque estratégico supuso una sofisticación en la comprensión de la decisión judicial, pues la concibió no solo como una cuestión binaria que se refleja en el actor favorecido. Una de sus conclusiones principales es que las ideas, perfiles y trayectorias de los operadores judiciales, así como los procesos de socialización, tienen un impacto considerable en el desempeño de los tribunales (Gonzalez-Ocantos, 2019). Tal y como ocurre en cualquier burocracia, esos procesos están condicionados por las estructuras organizacionales que, durante su proceso de institucionalización, los poderes judiciales establecen para el ejercicio de funciones administrativas y jurisdiccionales.

Nuestro interés en este trabajo no son todas esas estructuras sino solo las que específicamente organizan el trabajo de las personas que se encargan de elaborar los proyectos de sentencias y criterios jurisprudenciales, a quienes se denomina secretarios, magistrados auxiliares, letrados o law clerks. En sintonía con la literatura sobre teoría organizacional, asumimos que la labor judicial está asociada a hábitos, rutinas y procesos cognitivos, cuya influencia es a su vez mediada por reglas formales e informales que, en conjunto, estructuran el trabajo de las organizaciones (Greenwood et al., 2017; Stevenson, 2000). Aunque en esa literatura no existe una definición única de estructura organizacional, esta noción regularmente se emplea para aludir a la forma en que se distribuyen, agrupan y coordinan las tareas y recursos al interior de las propias organizaciones (Robbins $\&$ Judge, 2017). ${ }^{3}$ En este estudio la concebimos como el conjunto de reglas y prácticas que determinan la especialización y departamentalización de las tareas, la definición y formalización de cadenas de mando y tramos de control, y la conformación de mecanismos centralizados o descentralizados de toma de decisiones (Peabody \& Rourke, 1965). ${ }^{4}$

Para un recuento de las nociones del concepto, véase Tran \& Tian (2013).

El concepto estructura organizacional, a diferencia del de diseño organizacional, alude no solo a las reglas formales definidas desde la cúspide de las organizaciones sino también a los patrones de interacción que se desarrollan en su interior, muchas veces en forma independiente a lo que dictan las normas (Stevenson, 2000). 
En las estructuras organizacionales del ámbito judicial subyacen pautas de comportamiento y visiones sobre la función jurisdiccional cuyo estudio permite conocer cómo se producen las decisiones y cómo los jueces ejercen sus funciones (Cortez Salinas, 2019). Las características de las estructuras con la que cuenta cada tribunal suponen un mayor o menor margen para que los jueces seleccionen a sus colaboradores e integren sus equipos. La forma en que lo hacen en la práctica forma parte de su conducta ya que esa selección de personas y organización del trabajo se realizan para conseguir fines específicos.

Uno de los incentivos de los jueces que se incorporan a las cortes supremas y constitucionales es leer la Constitución y plasmar su visión sobre la división de poderes y los derechos humanos. Después de un proceso constituyente o de una nueva integración de las Cortes, existe la posibilidad de ser creativo en la lectura de los frenos y contrapesos, o los derechos humanos. En América Latina se ha comprobado que la llegada de nuevos jueces constitucionales fue un factor clave en la generación de jurisprudencia favorable a los derechos humanos (Couso \& Hilbink, 2010; Hilbink, 2014).

Cuando un nuevo juez llega a un tribunal e intenta introducir una nueva visión del derecho sus principales aliados son los secretarios o letrados, pues son ellos quienes los apoyan en la revisión de los casos y en quienes delegan la redacción de sentencias y votos particulares (Cortez Salinas, 2020). Dado que estas personas tienen muchas veces mayor conocimiento de los litigios, son ellas quienes frecuentemente terminan por definir el sentido de las resoluciones $y$, por tanto, quienes se hacen cargo en última instancia de interpretar el derecho.

Pese a la importancia del trabajo de estas personas, la investigación sobre sus trayectorias profesionales y desempeño es todavía limitada. En todo caso, las aportaciones más importantes provienen de los estudios sobre los law clerks en Estados Unidos. Estos estudios han reconstruido la historia de esa figura (Peppers, 2006; Peppers \& Ward, 2012; Ward \& Weiden, 2006), explicado cómo y por qué los jueces reclutan a personas con perfiles determinados (Baum, 2014; Bonica et al., 2016; Ditslear \& Baum, 2001), explorado su contribución en la selección de casos de la Corte Suprema (Black \& Boyd, 2012; Black et al., 2014), e inclusive identificado el impacto de su trabajo en las decisiones de fondo (Kromphardt, 2015; Rosenthal \& Yoon, 2010; Yoon, 2014). Con todo, salvo el trabajo de Kromphardt (2014) acerca de la integración de equipos en la Corte Suprema con law clerks poseedores de orientaciones ideológicas distintas a las de los jueces, prácticamente no existen estudios empíricos que exploren la relación entre estructura organizacional y secretarios.

Comprender la conducta judicial en los sistemas jurídicos de la tradición de derecho civil como los de América Latina también requiere de analizar los 
aspectos internos de las Cortes, particularmente en las estructuras organizacionales que condicionan la producción de las decisiones. En el caso de Colombia se sabe que los letrados han contribuido a dar continuidad a las innovaciones de la Corte Constitucional en materia de derechos humanos (Landau, 2015). También se conoce el impacto del género en la selección de letrados del Supremo Tribunal Federal de Brasil (Szmer et al., 2014), o las funciones divergentes que realizan los secretarios adscritos a las secretarías judiciales respecto de aquellos que laboran directamente en las vocalías de los jueces de la Corte Suprema de Argentina (Barrera, 2008).

En México, los Secretariados de Estudio y Cuenta han realizado tres funciones vitales para la SCJN: introducir distintas miradas a los problemas jurídicos, reducir los costos de aprendizaje de rutinas, y ser fuentes de información para la difusión de nuevas ideas jurídicas, lo que permitió la renovación de criterios jurisprudenciales (Cortez-Salinas, 2019). Hasta ahora, sin embargo, se sabe muy poco sobre el impacto de los secretarios en la elaboración de las sentencias y, menos aún, sobre el que produce la organización del trabajo judicial.

Nosotros sostenemos que un aspecto determinante de ese impacto es el grado de control que los jueces que integran órganos colegiados como las cortes supremas y constitucionales tienen sobre el trabajo de los secretarios, el cual depende en gran medida de su adscripción dentro o fuera de sus equipos. La revisión de la literatura sobre secretarios y magistrados auxiliares nos ha permitido identificar dos clases generales de estructuras organizacionales: las descentralizadas y las centralizadas. Las primeras son aquellas en las que cada juez tiene la posibilidad de organizar su equipo de trabajo y se encarga de la selección y contratación de sus colaboradores. En este modelo, los secretarios están adscritos directamente a los equipos de los jueces y, por tanto, existe un control y supervisión directa de su trabajo. Las centralizadas, por su parte, son aquellas donde los secretarios están adscritos a un área que trabaja para todos los jueces, lo que hace que la supervisión del trabajo sea indirecta.

El cuadro 1 resume las características de cada clase y ofrece ejemplos de su aplicación. Allí se aprecia que en la actualidad son más comunes las estructuras descentralizadas que se utilizan, por ejemplo, en las cortes supremas de Estados Unidos y Argentina, o las cortes constitucionales de Colombia e Italia. Las estructuras centralizadas, por su parte, existen en órganos como el Consejo Constitucional francés, donde, para procesar con velocidad los casos en que se solicita el control ex ante de constitucionalidad, se cuenta con un área que se encarga de elaborar los proyectos para todos los jueces. Otro ejemplo es el Tribunal Constitucional español cuya Secretaría General Adjunta se encarga de coordinar a los letrados del tribunal que además son seleccionados mediante concursos de oposición. 
Cuadro 1. Clases de estructuras organizacionales vinculadas a la elaboración

de sentencias

\begin{tabular}{|c|c|c|}
\hline & Características & Ejemplos \\
\hline Descentralizadas & $\begin{array}{l}\text { Supervisión directa del trabajo } \\
\text { de los secretarios }\end{array}$ & $\begin{array}{l}\text { Argentina (Barrera, 2008); Colombia (Landau, 2015); Esta- } \\
\text { dos Unidos (Peppers, 2006; Ward \& Weiden, 2006); Italia } \\
\text { (Pasquino, 2016); México (ponencias) (Cortez Salinas, 2020) }\end{array}$ \\
\hline Centralizadas & $\begin{array}{l}\text { Supervisión indirecta del traba- } \\
\text { jo de los secretarios }\end{array}$ & España; Francia (Pasquino, 2016); México (UCCyAl) \\
\hline
\end{tabular}

Fuente: Elaboración propia.

Un modelo descentralizado supone flexibilidad en la conformación de los equipos y facilita la incorporación de colaboradores con trayectorias académicas y profesionales diversas, de este modo crea condiciones para que la pluralidad de visiones sobre el derecho quede plasmada en las sentencias. En cambio, las estructuras centralizadas dificultan el control del reclutamiento, la conformación de los equipos y el trabajo de los colaboradores. En estos casos, los jueces ceden parte de su autonomía para facilitar que el órgano colegiado cuente con mecanismos generales de construcción de sentencias. Además, como explicaremos al analizar la experiencia de la UCCyAI, esta clase de estructuras puede también propiciar una amplia delegación de funciones jurisdiccionales, limitar la diversidad en las visiones del derecho y, en última instancia, generar uniformidad en las decisiones y criterios interpretativos.

\section{Diseño de investigación y fuentes de información}

Esta investigación analiza la creación y funcionamiento de la UCCyAI para construir inferencias descriptivas sobre su desempeño. Nuestro propósito es contribuir al estudio de la SCJN y, de manera derivada, a la investigación de la relación entre estructuras organizacionales, secretarios y justicia constitucional. Este trabajo es, por tanto, un estudio de caso diacrónico, es decir, un estudio en profundidad de un caso específico a lo largo del tiempo cuyo análisis puede ser útil para comprender otros (Gerring, 2007). Para analizar la experiencia de la Unidad construimos un diseño de investigación que involucra el uso de herramientas cualitativas y cuantitativas, tal y como una abundante literatura ha sugerido para este tipo de trabajos (Fearon \& Laitin, 2008; Goertz, 2017).

En particular, para reconstruir la historia de la Unidad, utilizamos entrevistas semiestructuradas, leyes y documentos oficiales y notas periodísticas. Con las entrevistas hemos buscado obtener información proveniente tanto de fuentes oficiales, como de actores que, por su actividad profesional, tuvieron contacto con el trabajo de dicha área. La revisión de documentos oficiales se 
concentró en los instrumentos legislativos que regulan tanto las acciones de inconstitucionalidad y las controversias constitucionales como la figura de secretario de Estudio y Cuenta, así como las normas expedidas por la sCjN respecto de la UCCyAI. Finalmente, la revisión hemerográfica consistió en recopilar las notas que dieron cuenta del trabajo de dicha unidad mediante búsquedas en las páginas de internet de dos diarios de circulación nacional: Reforma y El Universal. 5

El componente cuantitativo consiste en una sistematización original del conjunto de acciones de inconstitucionalidad y controversias constitucionales resueltas en el periodo 1995-2005, esto es, a partir de la entrada en vigor de la reforma judicial de 1994 y hasta el año en que se disolvió la UCCyAI. La sistematización incluyó el registro de los datos generales del expediente: número, fechas de ingreso y resolución, actor, autoridad demandada, norma o acto impugnado, materia de la demanda, sentido de la resolución, ministro ponente, entre otros; el nombre del secretario o los secretarios de Estudio y Cuenta que participaron en la elaboración de cada sentencia; y las votaciones, votos particulares y tesis aisladas y jurisprudenciales correspondientes a cada sentencia. Las fuentes de información de los datos generales fueron las bases sobre acciones de inconstitucionalidad y controversias constitucionales, disponibles en el portal de estadística judicial de la $\operatorname{SCJN} ;^{6}$ en tanto que las referentes a los secretarios de Estudio y Cuenta, votaciones y votos particulares, fueron las sentencias obtenidas mediante la consulta de la sección "Sentencias y datos de expedientes" de la página de la scjn. ${ }^{7}$

La anómala práctica de atribuir — total o parcialmente— la elaboración de las sentencias al titular de la Unidad fue el elemento que nos permitió distinguir entre estructuras organizacionales: centralizada, cuando las sentencias estuvieron efectivamente a cargo de esa unidad; y descentralizada, cuando fueron elaboradas únicamente por secretarios de Estudio y Cuenta adscritos a las oficinas de los ministros (ponencias). La estructura organizacional es el criterio con el que analizamos la delegación y al que ponderamos en función de otros - año de resolución, ministro ponente, categoría de actor-, mediante el uso de herramientas de estadística descriptiva - frecuencias y distribuciones condicionales, principalmente- La uniformidad la evaluamos a partir de tres categorías: invalidez de la norma o acto impugnado, unanimidad en las votaciones y votos particulares. La primera sirve como indicador del sentido de las decisiones; las segundas, como indicadores del nivel de disidencia detrás de ellas.

\footnotetext{
Disponibles en https://www.eluniversal.com.mx/, y https:/www.reforma.com/, respectivamente.

En https://estadisticajudicial.scjn.gob.mx/alex/Default.aspx

Disponible en http://www2.scjn.gob.mx/ConsultaTematica/PaginasPub/TematicaPub.aspx
} 


\section{De la descentralización a la centralización de la elaboración de sentencias}

El crecimiento exponencial en el número de litigios, juzgados y tribunales es, posiblemente, la evidencia más clara de la institucionalización y burocratización de la judicatura mexicana. Otro de los rastros que esos procesos van dejando a lo largo del tiempo son las regulaciones relacionadas con el personal que apoya a los ministros. Esta sección examina la evolución de esas disposiciones para explicar por qué la creación de la UCCyAI a la entrada en vigor de la reforma judicial de 1994 resultó paradójica. La paradoja radica en que los ministros que se hicieron cargo de la instrumentación de esa reforma y, por tanto, de encabezar a un tribunal con poderes de control de constitucionalidad sin precedentes, optaron por conformar un área fuera de su supervisión directa, la cual estuvo a cargo de las sentencias derivadas del ejercicio de esos nuevos mecanismos de control de constitucionalidad. Después, con base en esa revisión, se reconstruye la historia y funciones que desempeñó la Unidad durante los diez años en que existió.

\section{La trayectoria de la figura de secretario de Estudio y Cuenta en la Suprema Corte de Justicia de la Nación}

Los Secretariados de Estudio y Cuenta son los principales aliados de los jueces para lograr sus objetivos. Cuando un juez ingresa a la Corte el primer recurso con el que cuenta es la organización del equipo de abogados con los que necesita trabajar. Los secretarios son quienes elaboran las sentencias, lo cual hace que su perfil y trayectorias académicas sean muy relevantes, más todavía si se considera que cumplen con las tareas de difundir ideas o aportar conocimiento sobre las rutinas y hábitos según los objetivos de cada juez (Cortez Salinas, 2020).

La Ley Orgánica del Poder Judicial de la Federación (LOPJF) ha sido el ordenamiento que regula a los funcionarios judiciales desde 1908. Hasta la fecha, han existido siete versiones de esa ley, las cuales han sido vez objeto de diversas reformas. ${ }^{8}$ En la trayectoria de ese ordenamiento se observa una progresiva consolidación de la figura de secretario de Estudio y Cuenta — formalmente incorporada en 1977, aunque previamente ya se habían introducido normas para regular el

8 Expedidas en 1908, 1917, 1928, 1934, 1936, 1988 y 1995. La primera no fue objeto de reforma, la segunda de dos, la tercera de ninguna, la cuarta de una, la quinta de 23, la sexta de cuatro, y la séptima, hoy vigente, de 34 . 
trabajo de las personas que colaboraban directamente con los ministros-, pero también de la gradual conformación de una estructura organizacional descentralizada y bajo la supervisión directa de los ministros: la ponencia.

Durante el siglo xx los ministros adquirieron cada vez mayores atribuciones no solo para conformar sus equipos, sino para incidir en la integración del resto de los órganos judiciales. Ello, al confluir con el crecimiento de la judicatura federal, propició que surgiera el modelo de reclutamiento y ascenso al que (Cossío-Díaz, 1996) denomina "tutorial". Bajo este modelo, los secretarios aprendían de los ministros rutinas y prácticas que les permitieron después convertirse en juzgadores federales. Con el tiempo, este modelo fue fundamental para que no se renovaran los criterios jurisprudenciales, pues los secretarios no eran portadores de nuevas ideas jurídicas y no se atrevían a desafiar a sus superiores (Cossío-Díaz, 1996). En este contexto fue que surgió el "pacto entre caballeros", una institución informal que se caracterizó por la rotación entre los ministros de las designaciones de jueces y magistrados (Pozas-Loyo \& RíosFigueroa, 2018).

Uno de los objetivos explícitos de la reforma judicial de 1994 fue terminar con las consecuencias perniciosas que produjo el modelo tutorial en el contexto de una judicatura en expansión. Aunque en aquel momento se buscó profesionalizar la carrera judicial mediante un sistema de reclutamiento y progreso profesional basado en el mérito, hasta ahora no se han conseguido desterrar las prácticas que se generaron durante años (Ríos Figueroa, 2018). Con todo, la reforma sí transformó a la SCJN, gracias, en buena medida, a que las innovaciones que introdujo en materia de control de constitucionalidad convergieron con un pluralismo político.

La reforma también buscó que los cargos de secretario de Estudio y Cuenta fueran ocupados por personas con carrera judicial, pero simultáneamente dio flexibilidad a los ministros para integrar sus equipos. Por un lado, determinó que los secretarios de Estudio y Cuenta debían ser designados por los ministros, formarían parte de la carrera judicial, y presentarían exámenes de aptitud ante el Instituto de la Judicatura Federal, siempre que así lo solicitaran los ministros. Por el otro, señaló que al menos dos terceras partes de los secretarios de Estudio y Cuenta de ministros debían ser personas que se hubieran desempeñado dos o más ańos como secretarios de Tribunal de Circuito o Juzgado de Distrito.

A partir de 2003, cuando iniciaron las rotaciones en la integración de la SCJN, comenzó a configurarse un modelo mixto, descentralizado y con supervisión directa, solo que ahora caracterizado por la integración de equipos con personas con experiencia y trayectorias diversas en el litigio, la académica y la propia judicatura (Cortez Salinas, 2020). Durante el tiempo en que existió la UCCyAI coexistieron en la SCJN dos estructuras organizacionales: 
centralizada para las acciones y controversias, y descentralizada para el juicio de amparo y el resto de los procedimientos. Es claro entonces que, en principio, la creación de una estructura centralizada resulta paradójica, pues cuando ocurrió la SCJN llevaba años elaborando las sentencias a través de las ponencias, es decir, mediante equipos adscritos, integrados y supervisados directamente por los ministros.

Diagrama 1. Dos clases de estructuras y tres modelos organizacionales

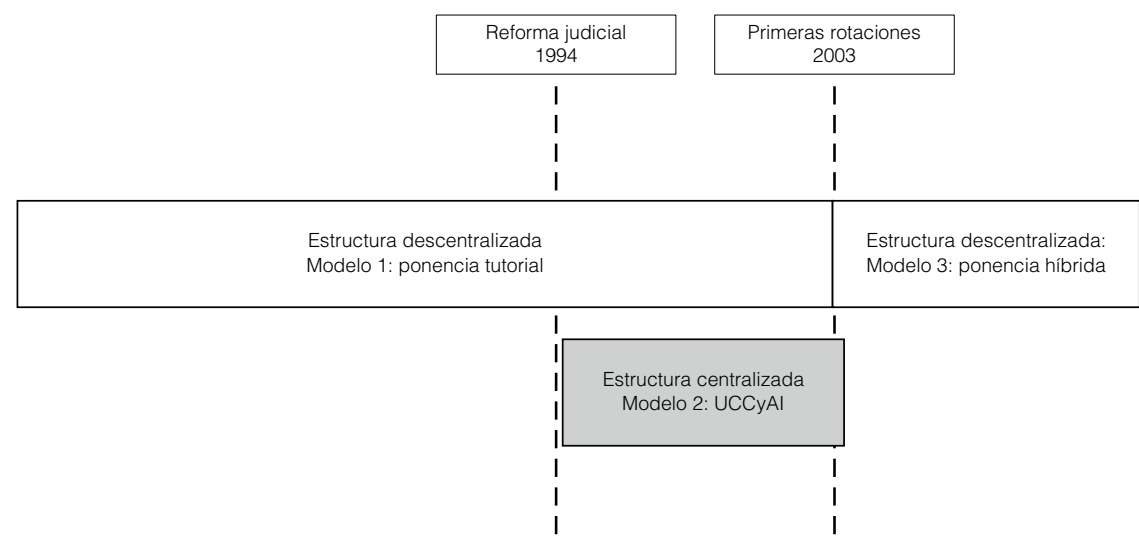

Fuente: Elaboración propia.

El diagrama 1 resume lo explicado e ilustra la forma en que se articularon los tres modelos organizacionales durante el siglo xx y lo que va del xxi. El primero es el modelo descentralizado o tutorial que predominó en la mayor parte del siglo xx y se caracterizó por un vínculo tutorial entre jueces y secretarios (Cossío-Díaz, 1996), y lazos de patronazgo en la carrera judicial (Pozas-Loyo $\&$ Ríos-Figueroa, 2018). El segundo modelo corresponde a la UCCyAI, es centralizado, surgió después de la reforma de 1994, se utilizó para elaboración de controversias y acciones de inconstitucionalidad, y coexistió con una estructura descentralizada en todo lo referente a los asuntos distintos a los originados en estos dos medios de control constitucional. El tercero es un modelo descentralizado de ponencia que inició con la renovación de jueces constitucionales en 2003, se caracteriza por una combinación de abogados de carrera judicial con gente con trayectoria en la academia y en el litigio profesional. Este modelo permitió la renovación de criterios jurisprudenciales en materia de derechos humanos en la Corte (Cortez-Salinas, 2020). 
La UCCyAI se creó formalmente con el Acuerdo 2/1998 que el Pleno de la SCJN expidió para abatir el rezago judicial (scjN, 1998a). Ese acuerdo, aprobado en el último año de la presidencia de José Vicente Aguinaco Alemán, adscribió esa unidad a la Subsecretaría General de Acuerdos, y determinó que debía integrarse por personal designado por el Pleno a propuesta de la Subsecretaría y del titular de la propia Unidad. También se crearon criterios para homologar la elaboración de las sentencias, y se sugirió a los ministros designar un coordinador de ponencia, para que diera seguimiento a los asuntos y fungiera como enlace con el resto de las áreas del tribunal.

La titularidad de la UCCyAI recayó originalmente en Osmar Armando Cruz Quiroz, hoy magistrado de Circuito. ${ }^{9}$ Sin embargo, de acuerdo con un entrevistado, dicha unidad comenzó a operar "por vías de hecho" desde 1996, bajo la coordinación del propio Cruz Quiroz (entrevistados 1 y 2), con la misión de tramitar las controversias constitucionales y acciones de inconstitucionalidad y elaborar los proyectos de resolución independientemente del ministro ponente designado (entrevistado 1). El trabajo del área cobró mayor visibilidad durante la administración de Genaro Góngora Pimentel, quien como presidente del Tribunal la dotó de mayor presupuesto y personal.

En 2000 se nombró como segundo y último titular a Pedro Nava Malagón, abogado por la Universidad Iberoamericana, con estudios de posgrado en amparo y derecho constitucional en la Universidad Panamericana, y trayectoria como secretario de Tribunal Colegiado. Al ańo siguiente, el Acuerdo General del Pleno 1/2001 reguló con mayor precisión el funcionamiento del área y la relación de su titular con los ministros (scjn, 2001). Dicho Acuerdo estipuló que el titular debía informar periódicamente al Pleno sobre los asuntos, indicando los nombres de los encargados de los proyectos, independientemente de si pertenecían a la UCCyAI o las ponencias. De acuerdo con una entrevista que Nava Malagón dio en 2001 a El Universal, con el fortalecimiento del área el ministro Góngora buscó lo siguiente:

Éste pretendía reunir a un grupo de especialistas con ciertas características muy definidas, creando una especie de "área de inteligencia". Los Secretarios de Estudio

9 El Informe de Labores de la sCjN correspondiente a 1998 es el primero que incluye información de las actividades de la UCCyAI. El anexo 5 de ese informe señala que el titular del área en ese ańo era ya Osmar Armando Cruz Quiroz (scjn, 1998b, p. 107). 
y Cuenta, adscritos a la Unidad, deberían de tener amplia experiencia y honorabilidad, sobre todo porque la información que se maneja es de lo más delicada. Todos los asuntos que se tratan están causando un problema social y deben tratarse cuidadosamente. Dos años después el equipo está conformado por 31 personas, y quien menos tiempo tiene en el Poder Judicial es 16 años (El Universal, 2001, 7 de mayo).

Las entrevistas realizadas a otros operadores jurídicos revelan que la Unidad daba trámite a todos los asuntos de manera uniforme, buscando que la SCJN no se contradijera en sus decisiones (entrevistados 3 y 4). En una entrevista para una publicación especializada en cuestiones jurídicas, Nava Malagón sostuvo sobre las funciones que realizaban lo que a continuación se transcribe: "[S]e elaboran los proyectos de resolución que se someterán a consideración del Pleno de esta Suprema Corte de Justicia de la Nación o de alguna de las sus salas. Es decir, en la Unidad se lleva a cabo el trámite de estos asuntos desde el momento en que se presenta la demanda hasta que se pone el expediente en estado de resolución" (Ruiz Soriano, 2002, s/p).

Durante su existencia, la UCCyAI contó con personal de carrera judicial y, por la relevancia de sus funciones, se convirtió en un espacio de negociación al que acudían gobernadores, legisladores y otros políticos a tratar asuntos en los que estaban involucrados (entrevistados 4 y 5). Los litigantes no solo buscaban a los ministros sino también al titular de la Unidad porque sabían que ahí se elaboraban las sentencias. Los secretarios escribían los proyectos y él los presentaba y negociaba con los ministros. Según reportan los entrevistados, algunos cambiaban aspectos de forma y otros simplemente firmaban (entrevistados 1,2 y 3$)$.

Uno de los problemas que generó esa estructura fue que los mismos secretarios, con las mismas herramientas jurídicas y, por tanto, con la misma visión del derecho constitucional, se hayan hecho cargo de una proporción muy amplia de las sentencias. Ello indica que los ministros fueron reticentes a plasmar su visión sobre el federalismo y la división de poderes en un contexto en mayor fragmentación política y de declive del partido hegemónico. La opción que encontraron fue delegar en esa nueva estructura organizacional la elaboración de las sentencias.

La Unidad fue disuelta en la presidencia de Mariano Azuela por medio del Acuerdo 7/2005 (scjn, 2005). El argumento fue que sus atribuciones se empalmaban con las de la Subsecretaría General de Acuerdos. Los secretarios que la integraban fueron reasignados a las ponencias o regresaron a los tribunales que los habían comisionado. Con todo, la UCCyAI dejó un rastro indeleble en la jurisprudencia de la SCJN, identificable en la peculiar práctica de que sus 
titulares firmaran la totalidad de los proyectos en cuya redacción participó total o parcialmente el personal del área.

\section{La labor de la Unidad de Controversias Constitucionales y Acciones de Inconstitucionalidad dentro de la Suprema Corte de Justicia de la Nación}

Una vez que describimos la historia de la UCCyAI y planteamos que su creación implicó la introducción de un segundo modelo de organización del trabajo judicial, en esta sección nos enfocamos en analizar su desempeño. Antes de hacerlo conviene recordar que las innovaciones de la reforma de 1994, lejos de quedar en el papel, permitieron procesar una cantidad sin precedentes de conflictos entre autoridades y actores políticos que antes transcurrían por otras vías. De hecho, mientras que entre la promulgación de la Constitución de 1917 y el año 1994 se presentaron apenas 63 controversias constitucionales (Cossío Díaz, 2008), en la década posterior a la reforma se promovieron más de mil expedientes de la competencia exclusiva de la SCJN.

\section{Delegación}

En el periodo en que existió la Unidad (1996-2005), la scjN analizó un total de 1119 asuntos originados en acciones de inconstitucionalidad y controversias constitucionales. De ellos, 944 culminaron con la emisión de una sentencia y, el resto, por cuestiones procesales, con acuerdos expedidos por los ministros, las Salas o el Pleno. De esos 944 asuntos, la Unidad se hizo cargo de 753, es decir, del 79.8\% del total del periodo. Estos datos muestran la dimensión significativa a la que ascendió la delegación de funciones en esa estructura organizacional centralizada.

La gráfica 1, que ilustra cómo se distribuyen en el tiempo esas 944 sentencias, confirma que el área comenzó a operar antes de su creación formal y deja ver el brusco descenso que provocó su disolución. Allí se aprecia que la delegación inició de manera súbita y alcanzó niveles pronunciados a partir de 1997, aun dejando de lado a las 320 controversias constitucionales que se promovieron contra la reforma constitucional en materia indígena de 2001. Esas controversias fueron resueltas al año siguiente de manera conjunta, aunque mediante sentencias individuales en las que la scjN consideró que no podía analizar de fondo la constitucionalidad de las reformas a la Constitución. Incluso sin considerar estos casos, durante sus años de funcionamiento, la UCCyAI se hizo cargo de siete de cada diez sentencias. 


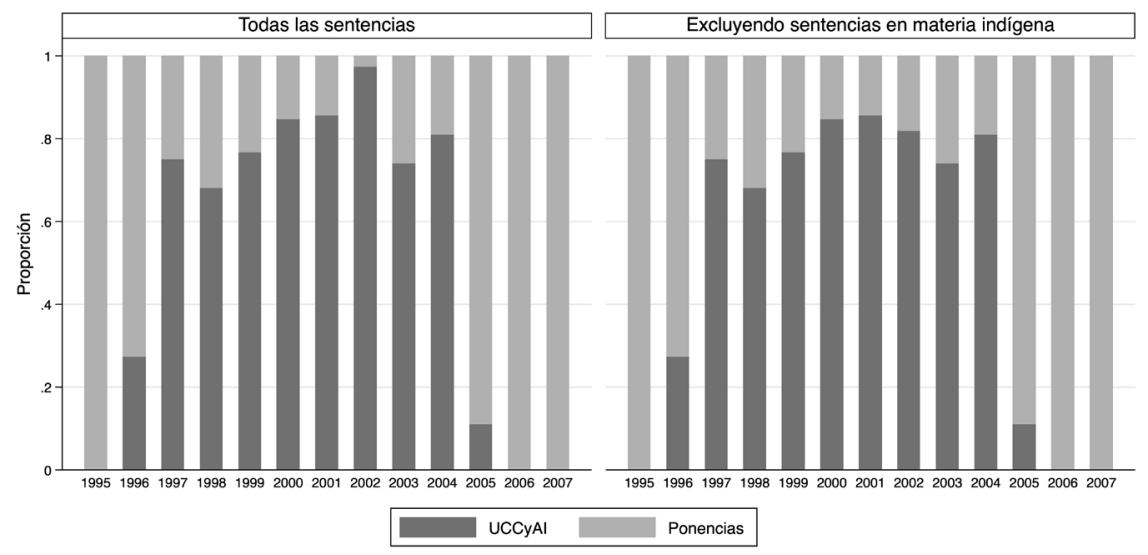

Fuente: Elaboración propia.

Esto datos indican que los ministros delegaron la elaboración de gran parte de las sentencias relacionadas con asuntos vinculados a la división de poderes y federalismo en un grupo reducido fuera de su supervisión directa. Esa delegación, sin embargo, no fue homogénea, tal como se ilustra en el cuadro 2, donde se observan diferencias importantes entre los 11 ministros designados en 1995 , y entre ellos y quienes se incorporaron a la SCJN a partir de 2003. Estas diferencias permiten identificar tres grupos: el primero, integrado por Román Palacios, Aguinaco Alemán, Castro y Castro, Silva Meza, Sánchez Cordero, Aguirre Anguiano y Ortiz Mayagoitia, presentó niveles superiores a la media; el segundo, conformado por Azuela Güitrón, Góngora Pimentel y Gudiño Pelayo, se distingue no solo por niveles inferiores a la media sino — como plantearemos más adelante al controlar por el tipo de actores- por una mayor heterogeneidad en función de los litigantes. Finalmente, el tercero lo integran Cossío Díaz, Luna Ramos y Valls Hernández, ministros que se incorporaron a la SCJN entre diciembre de 2003 y octubre de 2004, razón por la que formaron parte del tribunal durante un lapso reducido del periodo en que existió la UCCyAI.

No identificamos una tendencia general al evaluar si la jerarquía de los litigantes tuvo un efecto en el comportamiento de los ministros o, más precisamente, al explorar si estos decidieron que sus equipos se hicieran cargo de los casos políticamente más prominentes. En el primer grupo se observan variaciones solo con Silva Meza y Ortiz Mayagoitia, quienes delegaron una proporción menor de asuntos de actores federales que de otras categorías, aunque superior a la media general. En el segundo grupo, las variaciones son más evidentes: con 
Díaz Romero la proporción fue similar para las tres categorías de actores; Góngora Pimentel delegó menos casos de actores federales; Azuela Güitrón hizo lo contrario, y Gudiño Pelayo no delegó ninguno de actores subnacionales, pero sí la mitad de los de actores federales y un cuarto de municipales. El tercer grupo también presenta divergencias: Cossío Díaz delegó una proporción mayor de casos de actores subnacionales que de federales y municipales; Luna Ramos, únicamente dos sentencias, una de un actor federal y otra de uno municipal, las cuales representaron una proporción de 0.333 y 0.125 de sus respectivas categorías; Valls Hernández, ponente en tres sentencias durante el periodo, delegó una que provino de un actor federal.

Cuadro 2. Sentencias por ministro ponente y estructura organizacional (1996-2005)

\begin{tabular}{lcccr}
\hline & $\begin{array}{r}\text { UCCyAl } \\
\text { (centralizada) }\end{array}$ & $\begin{array}{r}\text { Ponencia } \\
\text { (descentralizada }\end{array}$ & Total & $\begin{array}{r}\text { Delegación } \\
\text { (UCCyAl/Total) }\end{array}$ \\
\hline Román Palacios (1995-2004) & 38 & 1 & 38 & 1.000 \\
Aguinaco Alemán (1995-2003) & 26 & 9 & 78 & 0.963 \\
Silva Meza (1995-2015) & 69 & 5 & 36 & 0.885 \\
Castro y Castro (1995-2003) & 31 & 9 & 51 & 0.861 \\
Sánchez Cordero (1995-2015) & 42 & 16 & 72 & 0.824 \\
Aguirre Anguiano (1995-2012) & 56 & 15 & 63 & 0.778 \\
Ortiz Mayagoitia (1995-2012) & 48 & 27 & 73 & 0.762 \\
Díaz Romero (1995-2006) & 46 & 22 & 37 & 0.630 \\
Azuela Güitrón (1995-2009) & 15 & 17 & 40 & 0.405 \\
Góngora Pimentel (1995-2009) & 23 & 16 & 30 & 0.575 \\
Cossío Díaz (2003-2018) & 14 & 40 & 61 & 0.467 \\
Gudiño Pelayo (1995-2010) & 21 & 12 & 14 & 0.344 \\
Luna Ramos (2004-2019) & 2 & 2 & 3 & 0.143 \\
Valls Hernández (2004-2014) & 1 & 191 & 623 & 0.333 \\
Total & 433 & & 0.693 \\
\hline
\end{tabular}

Nota: Los cálculos excluyen las sentencias relacionadas con la reforma constitucional en materia indígena de 2001. Fuente: Elaboración propia.

Aunque no fue posible detectar una tendencia general, los datos de algunos ministros apuntan hacia un comportamiento estratégico al definir qué asuntos delegar o, más precisamente, hacia un mayor interés en controlar la resolución de casos de actores más poderosos. Esto no supone necesariamente que el resto no hayan actuado también estratégicamente sino que, en todo caso, sus objetivos fueron distintos. Con todo, Góngora Pimentel se distingue del resto por la ostensible diferencia en la proporción que corresponde a actores federales. Esto resulta 
paradójico si se advierte que fue durante su presidencia cuando se fortaleció a la Unidad con mayores recursos financieros y humanos. Ello bien pudo resultar de una intención deliberada por expandir su influencia sobre las decisiones en acciones y controversias mediante la UCCyAI; sin embargo, para saberlo con certeza haría falta evidencia de la que no disponemos hasta ahora.

Ahora bien, las dinámicas de la delegación son aún más claras cuando se detalla la información por secretario de Estudio y Cuenta. En 406 de las 944 sentencias del periodo 1996-2005 se atribuyó la participación en la redacción de las sentencias a una sola persona, a dos en 529 , a tres en seis y a cuatro en tres. De los 406 casos con el nombre de un solo secretario, 252 corresponden a la Unidad, en 91 de ellos aparece el nombre de Osmar Armando Cruz Quiroz y en 161 el de Pedro Alberto Nava Malagón. A ellos se suman 501 en los que el nombre de ambos apareció junto al del de otras personas: seis en el caso del primero (todos con Nava Malagón), y 495 en el del segundo. En total, la participación de Nava Malagón se reconoce en 662 sentencias, las cuales representan $70.1 \%$ del total del periodo.

El diagrama 2 ilustra la distribución de las sentencias entre los 85 secretarios que participaron en su elaboración durante el periodo en que la UCCyAI estuvo en operaciones. Allí se aprecia con claridad que la delegación se concentró en un grupo reducido de personas. Mientras que 42 de esos 85 secretarios firmaron solo un expediente, otros tuvieron una participación significativa. En la elaboración de las 753 sentencias a cargo de la Unidad estuvieron involucrados, además de Cruz Quiroz y Nava Malagón, otros 12 secretarios. Algunos como Santos Pérez y García Velasco estuvieron adscritos a ella, en tanto que otros como María Amparo Hernández Chong Cuy, Raúl Manuel Mejía Garza o Roberto Lara Chagoyán fueron colaboradores de otros ministros.

Ciertamente, la participación en la redacción de los proyectos de personas adscritas tanto a la Unidad como a las ponencias habla, por un lado, del interés de algunos ministros por incidir mediante sus secretarios en el trabajo de esa área y, por el otro, de lo persistente de la práctica de documentar la participación de quienes fueron sus titulares. Esta información ofrece indicios de las tensiones que produjo la delegación de funciones en una estructura centralizada como lo fue la Unidad. Es importante tener en cuenta que en la disolución de esta pudo haber tenido mucho que ver el retiro en 2003 de Aguinaco Alemán y Castro y Castro, así como el fallecimiento de Román Palacios en 2004, tres de los cuatro ministros con las proporciones más altas de delegación. El espacio que dejaron pudo haber supuesto que esa área perdiera el respaldo de tres de sus aliados más importantes. Y, según lo indican los datos, esa pérdida pudo no haber sido compensada con el mismo nivel de apoyo de los ministros que se incorporaron a la Corte en 2003 y 2004. 
Diagrama 2. Sentencias por ministro ponente, estructura organizacional y secretario de Estudio y Cuenta (1996-2005)

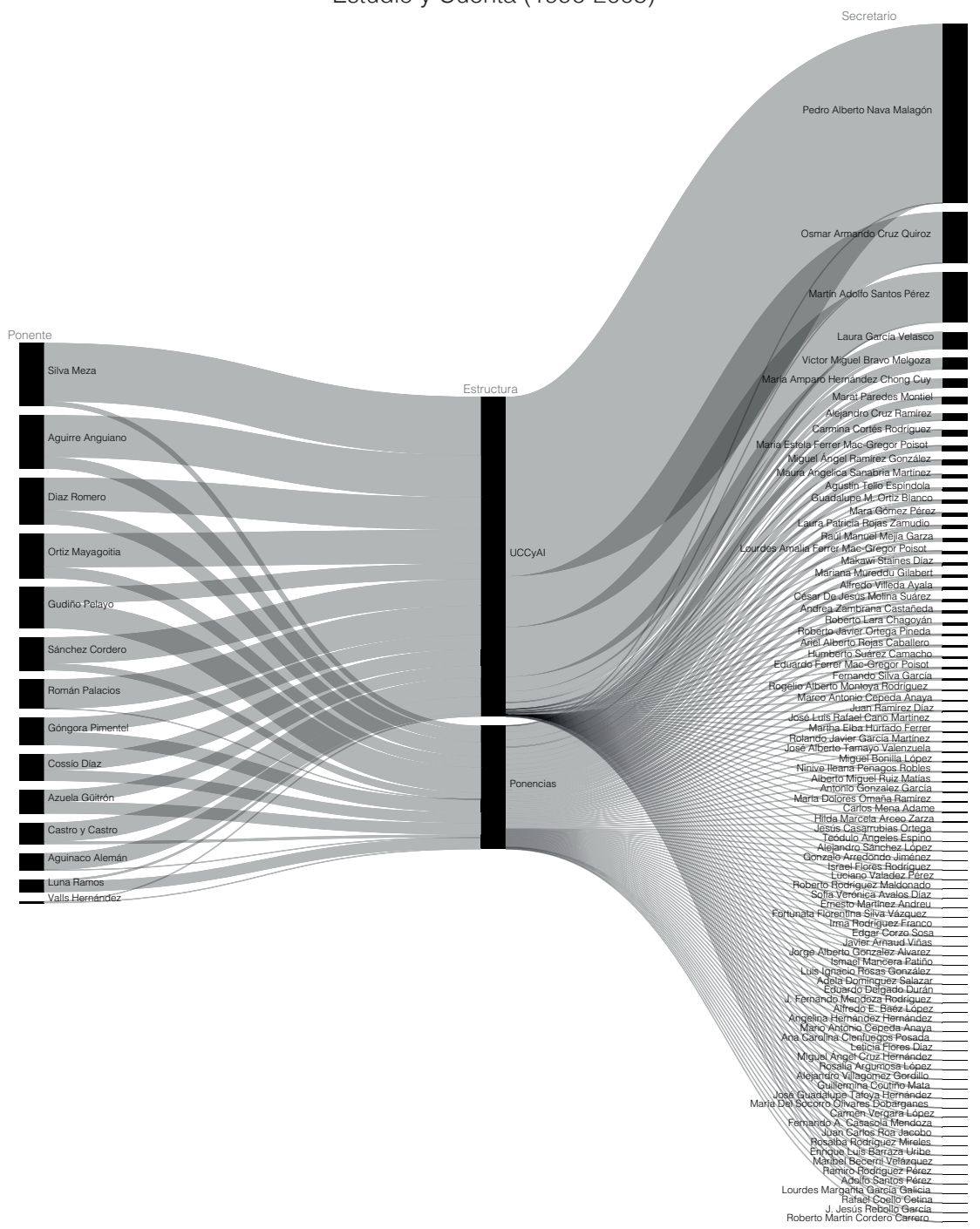

Nota: Los cálculos excluyen las sentencias relacionadas con la reforma constitucional en materia indígena de 2001. Fuente: Elaboración propia.

\section{Uniformidad}

Los datos presentados en la sección previa revelan las amplias dimensiones que alcanzó la delegación de la elaboración de sentencias en la Unidad. Esos 
datos, no obstante, por sí mismos no permiten conocer las consecuencias que dicha delegación produjo en las sentencias que expidió la scjN en los años en que contó con esa área. El propósito de esta sección es abordar tal cuestión mediante la revisión de los tres aspectos vinculados a la toma de decisiones del tribunal que describimos en la segunda sección: invalidez de las normas o actos impugnados, unanimidad de las votaciones y votos particulares.

Cuadro 3. Invalidez, unanimidad y votos particulares por estructura organizacional y categoría de actor (1996-2005)

\begin{tabular}{|c|c|c|c|c|}
\hline Estructura & $\begin{array}{r}\text { Cantidad } \\
\text { de sentencias }\end{array}$ & $\begin{array}{r}\text { Invalidez } \\
\text { (proporción) }\end{array}$ & $\begin{array}{l}\text { Unanimidad } \\
\text { (proporción) }\end{array}$ & $\begin{array}{r}\text { Votos particulares } \\
\text { (proporción) }\end{array}$ \\
\hline \multicolumn{5}{|c|}{ Todos los actores } \\
\hline UCCyAl & 432 & 0.266 & 0.880 & 0.141 \\
\hline Ponencia & 191 & 0.351 & 0.712 & 0.288 \\
\hline Total & 623 & 0.292 & 0.828 & 0.186 \\
\hline \multicolumn{5}{|c|}{ Actores federales } \\
\hline UCCyAl & 124 & 0.403 & 0.839 & 0.202 \\
\hline Ponencia & 45 & 0.533 & 0.600 & 0.378 \\
\hline Total & 169 & 0.438 & 0.775 & 0.249 \\
\hline \multicolumn{5}{|c|}{ Actores subnacionales } \\
\hline UCCyAl & 92 & 0.304 & 0.826 & 0.826 \\
\hline Ponencia & 48 & 0.333 & 0.750 & 0.729 \\
\hline Total & 140 & 0.314 & 0.800 & 0.793 \\
\hline \multicolumn{5}{|c|}{ Actores municipales } \\
\hline UCCyAl & 214 & 0.173 & 0.930 & 0.911 \\
\hline Ponencia & 98 & 0.276 & 0.745 & 0.745 \\
\hline Total & 312 & 0.205 & 0.829 & 0.859 \\
\hline
\end{tabular}

Nota: Los cálculos excluyen las sentencias relacionadas con la reforma constitucional en materia indígena de 2001 e incluyen los dos expedientes asociados a actores no legitimados, pero no se desglosan porque representan una proporción limitada del universo de análisis.

Fuente: Elaboración propia.

El principal hallazgo de este análisis es que existen diferencias considerables en función de la estructura organizacional. En cuanto a la invalidez, como se muestra en el cuadro 3, la proporción fue mayor para las ponencias (0.351) que la que correspondió a la Unidad (0.266). De hecho, el contraste entre ambas estructuras permanece cuando controlamos por la jerarquía de los actores, lo cual indica que la scjN invalidó las normas o actos controvertidos en una proporción menor cuando la UCCyAI estuvo a cargo de las sentencias, pero también que las características de los litigantes tuvieron un peso en las decisiones. 
Esto quiere decir que la estructura organizacional importa. La proporción de sentencias en las que declaró la invalidez se incrementa conforme aumenta la jerarquía de los actores. Y esos incrementos son mucho más notables cuando la UCCyAI elaboró las sentencias.

El cuadro también muestra la escasa disidencia que existió en la SCJN durante el periodo 1996-2005. Dejando de lado los expedientes relacionados con la reforma indígena, la proporción de sentencias aprobadas por unanimidad fue de 0.828 . Esta cifra se eleva cuando la Unidad se hizo cargo de su elaboración $(0.880)$ y disminuye cuando no fue así (0.712). Además, las diferencias permanecen cuando se controla por la jerarquía de los actores, lo cual habla de nueva cuenta de que, aun ponderando el peso de los actores, la estructura organizacional estuvo asociada a niveles más altos de unanimidad.

La poca disidencia también es identificable en los votos particulares. La emisión de este tipo de textos es un indicador de que los ministros decidieron que la disidencia no solo quedara asentada en las votaciones sino en documentos independientes a las sentencias o, en su caso, que pese a haber coincidido con el sentido de las resoluciones, hayan considerado necesario documentar las diferencias con los razonamientos jurídicos detrás de esas resoluciones. Nuestro análisis revela que los ministros emitieron uno o más votos en el $43 \%$ de las 944 sentencias del periodo. Pero una vez que se excluye el gran paquete de decisiones vinculadas a la materia indígena, esa proporción disminuye a 18.6\%. De nueva cuenta, la disidencia fue mayor para las ponencias que para la Unidad, pues la proporción de sentencias con votos particulares para la primera fue 0.288 y para la segunda 0.141 . De hecho, tres cuartas partes de las 351 sentencias elaboradas por esa área con votos particulares corresponden a la reforma indígena.

En conjunto, los datos sobre invalidez, unanimidad y votos particulares muestran que la estructura organizacional no es una cuestión inocua para la elaboración de sentencias ni para las decisiones del tribunal. Y no lo es porque, a la luz de la experiencia mexicana en los años en que existió la UCCyAI, se observan diferencias significativas que en última instancia indican lo importante que es la lectura y visión del derecho de las personas que escriben los documentos que plasman los resultados de los procedimientos judiciales. Podría decirse, siguiendo a González-Ocantos (2016), que la Suprema Corte mexicana, en la primera década de vigencia de la reforma judicial de 1994, se expresó predominantemente a partir de las mismas preferencias legales y con base en ellas resolvió buena parte de los conflictos relacionados con el federalismo y la división de poderes.

Esas preferencias no solo generaron uniformidad sino que fueron producto de un conjunto de decisiones que implicaron una considerable delegación de las potentes atribuciones que había producido esa misma reforma. Explorar las 
causas que a nivel individual propiciaron la delegación trasciende los objetivos de este trabajo. Esta tarea, sin embargo, parece que podría arrojar resultados útiles para comprender el comportamiento judicial en un periodo específico de la historia mexicana, así como para profundizar en el conocimiento de los factores internos de los tribunales que condicionan la conducta de los jueces.

\section{Conclusiones}

Observar los procesos que se realizan al interior de las instituciones públicas en la toma de decisiones es fundamental para comprender cómo y por qué esas decisiones se producen. La observación de esos procesos es aún más relevante en el caso de los tribunales - en especial en las cortes supremas y constitucionales - ya que su grado de especialización y la tendencia a mostrarse públicamente como autoridades ajenas a procesos sociales y políticos ha hecho que sean menos permeables al escrutinio de la ciudadanía y menos accesibles para la investigación especializada. Aunque ese hermetismo dificulta el trabajo académico, ello no implica que las personas que forman parte de las burocracias judiciales no desempeñen un papel fundamental en los resultados de la labor de los tribunales.

En línea con los esfuerzos que en los años recientes se han hecho por abrir la "caja negra" de los poderes judiciales (Gonzalez-Ocantos, 2019), este artículo ha explorado la relevancia de las estructuras organizacionales en las decisiones de los órganos de justicia constitucional, utilizando como estudio de caso la experiencia de la Unidad de Controversias Constitucionales y Acciones de Inconstitucionalidad en la sCJN. La UCCyAI fue una estructura centralizada, caracterizada porque la supervisaban indirectamente los jueces, en la que los secretarios estuvieron adscritos a un área que trabajó para todos los jueces, en un modelo donde estos últimos no tuvieron control directo sobre la forma en la que se elaboraban las sentencias judiciales.

La sistematización de más de mil expedientes identificó que los ministros designados en 1995 para instrumentar una reforma que estableció un contexto propicio para generar una nueva lectura de la Constitución optaron por no seguir por esa vía sino por delegar en la Unidad funciones jurisdiccionales muy amplias. En lugar de plasmar su visión sobre la división de poderes, el federalismo y la división de poderes, los jueces construyeron una estructura organizacional que adquirió un peso específico en la resolución de casos relacionados con temas fundamentales.

La delegación fue visible por el hecho de que la UCCyAI se encargó de redactar el 80\% de las 944 sentencias que el tribunal aprobó entre 1996 y 2005. 
Entre los mismos jueces existe variación pues los hubo que delegaron la elaboración de todas o prácticamente todas las sentencias en las que fueron ponentes (Román Palacios, Aguinaco Alemán, Silva Meza, Castro y Castro, Sánchez Cordero, Aguirre Anguiano y Ortiz Mayagoitia); otros que lo hicieron en menor proporción como Azuela Güitrón, Góngora Pimental y Gudiño Pelayo; y otros más que no pertenecieron a la integración de 1995 y que por eso formaron parte del tribunal durante un lapso corto del periodo en que existió la Unidad (Cossío Díaz, Luna Ramos y Valls Hernández).

La configuración de la estructura organizacional centralizada que fue la Unidad también produjo uniformidad en las decisiones del tribunal. Esa uniformidad es identificable en la proporción limitada de sentencias en las que se declaró la invalidez de las normas o actos reclamados (29.2\%), la cual fue aún menor cuando la elaboración de ellas estuvo a cargo de la UCCyAI (26.6\%). La uniformidad es también evidente en la poca disidencia que se presentó al interior del tribunal, ya que el $82.8 \%$ de las sentencias de acciones de inconstitucionalidad y controversias constitucionales emitidas en el periodo de estudio se aprobaron por unanimidad y solo $18.6 \%$ fueron acompañadas de votos particulares. De nueva cuenta, la unanimidad fue mayor en el caso de la Unidad $(88.0 \%)$ y menor la proporción de votos particulares (14.1\%).

La principal contribución de este trabajo es la investigación empírica sobre la Suprema Corte de Justicia mexicana. La literatura sobre este tema ha puesto énfasis en los aspectos externos al tribunal como factores determinantes del comportamiento de sus integrantes (Ansolabehere, 2007; Cortez Salinas, 2014; Magaloni et al., 2011; Ríos Figueroa, 2004, 2016; Saavedra-Herrera, 2013), sin prestar suficiente atención a factores internos, en especial, a la organización del trabajo judicial. Los hallazgos de esta investigación complementan los planteamientos de esa literatura mostrando el peso específico que tuvo una estructura organizacional determinada en las decisiones de la SCJN en la primera década de vigencia de la reforma judicial de 1994. En otras palabras, nuestros hallazgos revelan que el desempeño de la Suprema Corte en esa coyuntura específica no puede ser explicado solamente considerando el impacto del proceso de crecimiento de la fragmentación política del país sino que también debe observarse la forma en que se construyeron las sentencias del tribunal. Esto no quiere necesariamente decir que el cambio político no haya sido relevante sino más bien que su influencia interactuó con las características de una estructura organizacional determinada.

Más allá del caso mexicano, este trabajo aporta a los estudios sobre los poderes judiciales en América Latina al ofrecer una categorización de las estructuras que se utilizan para organizar esos equipos. Estas estructuras pueden ser centralizadas y descentralizadas. En las primeras, los jueces no tienen control directo sobre sus 
colaboradores pues existe un órgano que labora para todos ellos; en las segundas, los jueces asumen el reclutamiento y control de su equipo de colaboradores. Adicionalmente, esta investigación muestra con claridad la enorme relevancia del análisis de los equipos de trabajo en el ámbito judicial. Este análisis será fundamental para complementar la comprensión de la conducta judicial.

El reto actual es generar estudios descriptivos sobre la forma en la que se organizan esos equipos y el perfil de las personas que los integran. Con base en ello será posible explicar el impacto de los letrados o los secretarios en la elaboración de las sentencias. Una tarea pendiente para el caso de México es analizar con mayor detalle la variación entre los jueces y precisar por qué unos jueces delegaron más que otros la elaboración de las sentencias judiciales. Por ahora, a cien años de la muerte de Max Weber, conviene subrayar una vez más la importancia de analizar a las burocracias y las persona que las conforman, para comprender cómo y por qué las instituciones estatales funcionan.

\section{Referencias}

\section{Bibliografía}

Ansolabehere, K. (2007). La politica desde la justicia. Cortes supremas, gobierno y democracia en Argentina y México. México: Flacso México/Fontamara.

Bárcena Arévalo, E. (2018). El oficio de juzgar, la Corte y sus cortesanos: estudio etnográfico de la Suprema Corte de Justicia de la Nación y su incorporación del derecho internacional de los derechos humanos. Tesis para obtener el grado de Doctora en Antropología, Centro de Investigaciones y Estudios Superiores en Antropología Social, México. https://ciesas .repositorioinstitucional.mx/jspui/bitstream/1015/657/1/TE\%20B.A.\%202018\% 20Erika\%20Barcena\%20Arevalo.pdf

Barrera, L. (2008). Files circulation and the forms of legal experts: agency and personhood in the Argentine Supreme Court. Journal of Legal Anthropology, 1(1), 3-24. https:/doi .org/10.3167/jla.2008.010101

Baum, L. (2014). Hiring Supreme Court Law Clerks: Probing the ideological linkage between judges and justices. Marquette Law Review, 98, 333. https://pdfs.semanticscholar.org/94cd/ 7970b936f01234e234ba15d428900caf7112.pdf

Black, R. C., \& Boyd, C. L. (2012). The role of Law Clerks in the US Supreme Court's agenda-setting process. American Politics Research, 40(1), 147-173. https://doi.org/10.1177\% 2F1532673X11401814 
Black, R. C., Boyd, C. L., \& Bryan, A. C. (2014). Revisiting the influence of Law Clerks on the US Supreme Court's agenda-setting process. Marquette Law Review, 98, 75. https://pdfs .semanticscholar.org/6bb2/f412d2a480fb5cc5006965c9fdf4b340752d.pdf

Bonica, A., Chilton, A. S., Goldin, J., Rozema, K., \& Sen, M. (2016). The political ideologies of law clerks. American Law and Economics Review, 19(1), 96-128. https://scholar.harvard .edu/msen/publications/law-clerks

Cortez Salinas, J. (2020). Ideas, innovación y cambio organizacional en la Suprema Corte de Justicia de la Nación. México: UnAm. https://biblio.juridicas.unam.mx/bjv/detalle-libro/5849ideas-innovacion-y-cambio-organizacional-en-la-suprema-corte-de-justicia-de-la-nacion

Cortez Salinas, J. (2019). Secretarios de Estudio y Cuenta en la Suprema Corte de México: Un actor esencial pero olvidado. Política y Gobierno, 26(2). http://www.politicaygobierno.cide .edu/index.php/pyg/article/view/1299/984

Cortez Salinas, J. (2014). Análisis cualitativo comparado: Las decisiones de la Suprema Corte de Justicia contra el ejecutivo en México. Revista Mexicana de Sociología, 76(3), 413-439. http://mexicanadesociologia.unam.mx/index.php/v76n3/107-v76n3-a3

Couso, J., \& Hilbink, L. (2010). Del quietismo al activismo incipiente: Las raíces institucionales e ideológicas de la defensa de los derechos en Chile. En G. Helmke, \& J. Ríos Figueroa (Eds.), Tribunales constitucionales en América Latina (pp.169-208). México: Poder Judicial de la Federación.

Cossío Díaz, J. R. (2008). La controversia constitucional. México: Porrúa.

Cossío Díaz, J. R. (1996). Jurisdicción federal y carrera judicial en México (Cuadernos para la Reforma de Justicia). México: UNAM.

Ditslear, C., \& Baum, L. (2001). Selection of Law Clerks and polarization in the US Supreme Court. The Journal of Politics, 63(3), 869-885. http://dx.doi.org/10.1111/0022-3816.00091

Fearon, J. D., \& Laitin, D. D. (2008). Integrating qualitative and quantitative methods. En J. M. Box-Steffensmeier, H. E. Brady \& D. Collier (Eds.), The Oxford handbook of political science. Nueva York: Oxford University Press. https://doi.org/10.1093/oxfordhb /9780199286546.003.0033

Gerring, J. (2007). Case study research: principles and practices. Cambridge: Cambridge University Press. https://doi.org/10.1017/CBO9780511803123

Goertz, G. (2017). Multimethod research, causal mechanisms, and case studies: An integrated approach: Princeton: Princeton University Press. https://doi.org/10.2307/j.ctvc77khf

J. Cortez Salinas, C. Saavedra Herrera | La sentencia es de quien la trabaja: estructura organizacional y justicia constitucional en México (1996-2005) | Perfiles Latinoamericanos, 29(58) | FLACSO México 
Gonzalez-Ocantos, E. (2019). Courts in Latin America. En H. E. Vanden \& G. Prevost (Eds.), The Oxford encyclopedia of Latin American Politics. Nueva York: Oxford University Press. https://doi.org/10.1093/acrefore/9780190228637.013.1680

González-Ocantos, E. (2016). Shifting legal visions: Judicial change and human rights trials in Latin America. Cambridge: Cambridge University Press. https://doi.org/10.1017/ CBO9781316535509

Greenwood, R., Oliver, C., Lawrence, T. B., \& Meyer, R. E. (2017). The Sage handbook of organizational institutionalism. Londres: Sage. https://dx.doi.org/10.4135/9781526415066

Helmke, G. (2005). Courts under constraints: judges, generals, and presidents in Argentina. Nueva York: Cambridge University Press. https://doi.org/10.1017/CBO9780511510144

Hilbink, L. (2014). Jueces y politica en democracia y dictadura: Lecciones desde Chile. México: Flacso México.

Iaryczower, M., Spiller, P. T., \& Tommasi, M. (2002). Judicial independence in unstable environments, Argentina 1935-1998. American Journal of Political Science, 46(4), 699-716. https: //doi.org/10.2307/3088428

Kromphardt, C. D. (2015). US Supreme Court law clerks as information sources. Journal of Law and Courts, 3(2), 277-304. https://doi.org/10.1086/682136

Kromphardt, C. D. (2014). Fielding an excellent team: Law Clerk selection and chambers structure at the US Supreme Court. Marquette Law Review, 98, 289. http://scholarship.law .marquette.edu/cgi/viewcontent.cgi?article $=5222 \&$ context $=$ mulr

Landau, D. E. (2015). Beyond judicial independence: The construction of judicial power in Colombia. Tesis para obtener el grado de Doctor en Gobierno, Harvard University, Cambridge. http://nrs.harvard.edu/urn-3:HUL.InstRepos:14226088

Magaloni, B., Magar, E., \& Sánchez, A. (2011). Legalist versus Interpretativist. The Supreme Court and the democratic transition in Mexico. En G. Helmke \& J. Rios Figueroa (Eds.), Courts in Latin America (pp. 187-218). Cambridge: Cambridge University Press.

Pasquino, P. (2016). ¿Cómo deciden las Cortes Constitucionales? Precedente. Revista Jurídica, 9, 9-44. https://doi.org/10.18046/prec.v9.2424

Peabody, R. L., \& Rourke, F. E. (1965). Public bureaucracies. En J. March (Ed.), Handbook of organizations (pp. 802-837). Nueva York: Rand McNally. 
Peppers, T. C. (2006). Courtiers of the marble palace: The rise and influence of the Supreme Court Law Clerk. Palo Alto: Stanford University Press. https://www.h-net.org/reviews/showrev .php?id=13185

Peppers, T. C., \& Ward, A. (2012). In Chambers: Stories of Supreme Court Law Clerks and Their Justices. Charlosttsville: University of Virginia Press. https://www.upress.virginia.edu/title 14226

Pou Giménez, F. (2016). Cambio constitucional y la arquitectura institucional de la Suprema Corte. En A. Castagnola \& S. López Noriega (Eds.), El rol de la Suprema Corte en la consolidación democrática de México (pp. 73-103). México: Tirant Lo Blanch. https://www.tirant .com/mex/libro/el-rol-de-la-suprema-corte-en-la-consolidacion-democratica-de-mexico -andrea-castagnola-9788491191100

Pozas-Loyo, A., \& Ríos-Figueroa, J. (2018). Anatomy of an informal institution: The 'Gentlemen's Pact'and judicial selection in Mexico, 1917-1994. International Political Science Review, 39(5), 647-661. https://doi.org/10.1177\%2F0192512118773414

Ríos Figueroa, J. (2004). El Surgimiento de un Poder Judicial efectivo en México: Gobierno dividido y toma de decisiones en la Suprema Corte de Justicia, 1994-2002. En C. E. Saavedra Herrera (Comp.), Veinte años no es nada: la Suprema Corte y la justicia constitucional antes y después de la reforma judicial de 1994 (pp. 397-426). México: scjn. https://www.sitios.scjn .gob.mx/cec/biblioteca-virtual/veinte-anos-no-es-nada

Ríos-Figueroa, J. (2016). Constitutional Courts as mediators: Armed conflict, civil-military relations, and the rule of law in Latin America. Nueva York: Cambridge University Press.

Ríos Figueroa, J. (2018). El déficit meritocrático. Nepotismo y redes familiares en el Poder Judicial de la Federación. México: Mexicanos contra la Corrupción y la Impunidad.

Robbins, S. P., \& Judge, T. A. (2017). Organizational behavior. Essex: Pearson. https://www .pearson.com/us/higher-education/product/Robbins-Organizational-Behavior-16th -Edition/9780133507645.html

Rosenthal, J. S., \& Yoon, A. H. (2010). Judicial ghostwriting: authorship on the Supreme Court. Cornell Law Review, 96, 1307. https://dx.doi.org/10.2139/ssrn.1668735

Saavedra-Herrera, C. (2013). Democracy, judicialisation and the emergence of the Supreme Court as a policy-maker in Mexico, Tesis para obtener el grado de doctor en Gobierno, The London School of Economics and Political Science, Londres. http://etheses.lse.ac.uk/970/

J. Cortez Salinas, C. Saavedra Herrera | La sentencia es de quien la trabaja: estructura organizacional y justicia constitucional en México (1996-2005) | Perfiles Latinoamericanos, 29(58) | FLACSO México DOI: dx.doi.org/10.18504/pl2958-002-2021 
Saavedra Herrera, C. (2020). Las llaves de la Suprema Corte: fragmentación política y litigio constitucional en México. Revista Mexicana de Sociología, 82(2). http://revistamexicanadesociologia .unam.mx/index.php/rms/article/view/58150

Scribner, D. (2010). The judicialization of (separation of powers) politics: Lessons from Chile. Journal of Politics in Latin America, 2, 71-97. https://doi.org/10.1177/1866802X 1000200303

Epstein, L., \& Knight, J. (1998). The choices justices make. Washington: Congressional Quarterly Press.

Stevenson, W. (2000). Organization design. En R. T. Golembiewski (Ed.), Handbook of organizational behavior (pp. 145-174). Nueva York: Routledge. https://doi.org/10.4324/ 9781482290011

Szmer, J. J., Kaheny, E. B., \& Christensen, R. K. (2014). Taking a dip in the Supreme Court Clerk Pool: Gender-Based discrepancies in Clerk selection. Marquette Law Review, 98, 261. https://pdfs.semanticscholar.org/29bb/88fda634d988771d5c1e36bc261f631cec51.pdf

Taylor, M. M. (2008). Judging policy: courts and policy reform in democratic Brazil. Palo Alto: Stanford University Press. https://doi.org/10.2307/j.ctvqsdqnr

Tran, Q., \& Tian, Y. (2013). Organizational structure: Influencing factors and impact on a firm. American Journal of Industrial and Business Management, 3(2), 229. https://doi. org/10.4236/ajibm.2013.32028

Ward, A., \& Weiden, D. L. (2006). Sorcerers' apprentices: 100 years of law clerks at the United States Supreme Court. Nueva York: New York University Press.

Yoon, A. (2014). Law Clerks and the institutional design of the federal judiciary. Marquette Law Review, 98, 131. http://scholarship.law.marquette.edu/cgi/viewcontent.cgi?article= 5217\&context $=$ mulr

\section{Instrumentos jurídicos y documentos expedidos por la Suprema Corte de Justicia de la Nación}

Suprema Corte de Justicia de la Nación (scjn). (1998a). Acuerdo General número 2/1998, del Tribunal Pleno, del día diez de marzo de mil novecientos noventa y ocho, para llegar al año 200 sin rezago. México: scjn. https://www.scjn.gob.mx/sites/default/files/acuerdos_generales/ documento/2016-11/Acuerdo021998_0.pdf 
Suprema Corte de Justicia de la Nación (scJN). (1998b). Informe rendido por el Señor Ministro José Vicente Aguinaco Alemán, Presidente de la Suprema Corte de Justicia de la Nación y del Consejo de la Judicatura Federal, al terminar el año de 1998. México: SCJN.

Suprema Corte de Justicia de la Nación (scjN). (2001). Acuerdo número 1/2001, de doce de febrero de dos mil uno, del Tribunal Pleno de la Suprema Corte de Justicia de la Nación, que establece reglas para acelerar el trámite y la resolución de las controversias constitucionales y las acciones de inconstitucionalidad. México: scjN. https://www.scjn.gob.mx/sites/default/files/ acuerdos_generales/documento/2016-11/Acuerdo012001_0.pdf

Suprema Corte de Justicia de la Nación (sCJN). (2005). Acuerdo número 7/2005, de ocho de marzo de dos mil cinco del Tribunal Pleno de la Suprema Corte de Justicia de la Nación, relativo a la estructura y a las atribuciones de la Subsecretaría General de Acuerdos de este Alto Tribunal. México: scjN. https://www.scjn.gob.mx/sites/default/files/acuerdos_generales/documento/ 2016-11/Acuerdo-7-2005_0.pdf

\section{Notas de prensa y publicaciones de divulgación}

Fuentes, V. (2005, 9 de marzo). Justifica la Corte retiro de área de controversias. Reforma.

Ruiz Soriano, R. (2002). Entrevista. En defensa de la Constitución. Pedro Nava Malagón. El mundo del abogado.

\section{Entrevistas}

Entrevistado 1. Entrevista realizada en la Ciudad de México, 8 de octubre de 2008.

Entrevistado 2. Entrevista realizada en la Ciudad de México, 10 de octubre de 2008.

Entrevistado 3. Entrevista realizada en la Ciudad de México, 6 de octubre de 2008.

Entrevistado 4. Entrevista realizada en la Ciudad de México, 9 de octubre de 2008.

Entrevistado 5. Entrevista realizada en la Ciudad de México, 6 de octubre de 2008.

J. Cortez Salinas, C. Saavedra Herrera | La sentencia es de quien la trabaja: estructura organizacional y justicia constitucional en México (1996-2005) | Perfiles Latinoamericanos, 29(58) | FLACSO México 